\title{
Perfil proteico de tilápia nilótica chitralada (Oreochromis niloticus), submetida ao estresse crônico por hipóxia
}

\author{
[Proteic electrophoretic profile of chitralada tilapia nilotic (Oreochromis niloticus), exposed \\ to hypoxia chronic stress] \\ D.C. Melo, D.A.A. Oliveira, M.M. Melo, D.V. Júnior, E.A. Teixeira, S.R. Guimarães \\ Escola de Veterinária - UFMG \\ Caixa Postal 567 \\ 31123-970 - Belo Horizonte, MG
}

\begin{abstract}
RESUMO
Avaliou-se a variação da resposta secundária ao estresse causado por hipóxia durante 18 dias, em sistema de recirculação, em uma linhagem de tilápia nilótica (Oreochromis niloticus), chitralada, refletida no perfil proteico eletroforético do peixe e avaliou-se a diferença entre sexos para essa resposta. Foram utilizados 126 peixes, sendo 60 machos e 66 fêmeas, ambos com média de peso de $800 \mathrm{~g}$. O estresse crônico por hipóxia alterou $(\mathrm{P}<0,05)$ os valores médios relativos de albumina, $\alpha+\beta$-globulinas e de $\gamma$ globulina, provocou alteração $(\mathrm{P}<0,05)$ nos níveis de proteína total relativo ao aumento no grupo dos machos, diminuição significativa dos valores médios absolutos de albumina devido à diminuição nas fêmeas e à diminuição de $\gamma$-globulina nos machos. As variantes proteicas, albumina e $\gamma$-globulina tiveram influência do sexo.
\end{abstract}

Palavras-chave: tilápia, perfil eletroforético, estresse, hipóxia

\begin{abstract}
This study evaluated the secundary response variation to hypoxia stress in a strain of chitralada nilotic tilapia (Oreochromis niloticus) during 18 days, in a recirculation system. The effects were measured by the proteic electrophoretic profile and the difference between the genders. One hundred twenty-six fish were used, 60 males and 66 females, both averaging $800 \mathrm{~g}$. The chronic hypoxia stress altered $(P<0.05)$ the relative values of albumin, $\alpha+\beta$-globulins, and $\gamma$-globulin; modified $(P<0.05)$ the levels of total protein due to an increase in the male group; significantly decreased of the absolute mean values of albumin due to a decrease in the female group; and decreased the $\gamma$-globulin values in males. The proteic profile, albumin, and $\gamma$-globulin were influenced by gender.
\end{abstract}

Keywords: tilapia, electrophoresis profile, stress, hypoxia

\section{INTRODUÇÃO}

As proteínas, compostos indispensáveis à vida, representam a base da estrutura de células, tecidos e órgãos. Funcionam como catalisadores enzimáticos nas reações bioquímicas, carreadores de muitos constituintes do plasma e na defesa do organismo como anticorpos. $\mathrm{Na}$ área de patologia de peixes, ocorrem muitas vezes dificuldades de se estabelecer um diagnóstico rápido e de baixo custo aos produtores. $\mathrm{O}$ perfil proteico eletroforético não fornece informações específicas, mas é útil no diagnóstico quando seus valores são analisados e associados ao quadro clínico, sendo importantes para o diagnóstico e o prognóstico de algumas enfermidades (Kaneko et al., 1997).

Os dois principais tipos de proteínas do plasma são albumina e globulinas. A albumina é uma lipoproteína de alta densidade, e sua síntese é influenciada pela nutrição, balanço hormonal, 
estado geral do fígado e estresse (Hasegawa et al., 2002). Suas funções estão relacionadas com o transporte de substâncias e com a regulação e a manutenção da pressão coloidosmótica sanguínea (Leite, 1995; Kaneko et al., 1997; Thrall, 2007). As globulinas abrangem proteínas que atuam no sistema imune, fatores de coagulação, enzimas e proteínas transportadoras. Geralmente, são classificadas em alfa, beta e gamaglobulinas (também denominadas imunoglobulinas), em função de sua mobilidade eletroforética (Gershwin, 1989; Kaneko et al., 1997; Godoy et al., 2006; Thrall, 2007). Ao contrário dos mamíferos e das aves que apresentam cinco tipos de imunoglobulinas (IgA, IgE, IgD, IgG e IgM), os peixes apresentam apenas um tipo, a IgM.

Em sistemas intensivos de criação de peixes, a ocorrência de situações estressantes é inevitável. Durante o período de criação, os animais são submetidos a inúmeros manejos e variações ambientais. As consequências são, geralmente, redução do crescimento e do ganho de peso, do desempenho reprodutivo e da resistência a patógenos. O somatório dessas mudanças é comumente referido como resposta ao estresse (Barton e Iwana, 1991). Vários estudos têm mostrado que o estresse exerce efeito depressivo sobre várias respostas imunológicas em peixes, como aumento nas proteínas totais séricas (Milligam e Wood, 1982; McDonald e Milligan, 1992) e diminuição na produção de anticorpos (IgM) e no número de células produtoras de anticorpos (Carlson et al., 1993).

Muitos estudos têm sido realizados com determinação das proteínas e seu valor no diagnóstico e no prognóstico das doenças em mamíferos e aves (Canavessi et al., 2000; Hasegawa et al., 2002; Godoy et al., 2006). Os poucos trabalhos existentes sobre perfil proteico eletroforético de peixes são referentes à administração de imunoestimulantes ou comparação entre espécies (Tinman et al., 2000; Palti et al., 2000). Porém, não existem estudos sobre a influência do estresse por hipóxia no perfil proteico eletroforético de tilápias.

Portanto, o presente trabalho teve como objetivo avaliar o perfil proteico eletroforético de tilápias da linhagem chitralada, submetidas ao estresse por hipóxia.

\section{MATERIAL E MÉTODOS}

Foram utilizados 126 peixes do gênero Oreochromis, linhagem chitralada, sendo 60 machos e 66 fêmeas, ambos com média de peso de $800 \mathrm{~g}$, oriundos da Fazenda Geneforte, localizada no município de Pedro Leopoldo, MG. Cada animal foi anestesiado com quinaldina ${ }^{1}$ $(0,5 \mathrm{~mL} / 10 \mathrm{~L})$ e identificado por um piercing numerado no opérculo. Os peixes, transportados para o Laboratório de Aquacultura (Laqua) da Escola de Veterinária da UFMG e mantidos em tanques de $0,4 \mathrm{~m}^{3}$ em sistema de recirculação com uma troca de água por hora $(400 \mathrm{~L} / \mathrm{h})$, durante duas semanas para aclimatação, receberam $1 \%$ do peso vivo de ração comercial, por dia para manutenção do peso.

Após o período de aclimatação, fêmeas e machos foram separados - 10 e 11 animais por tanque, respectivamente, de modo que essa estocagem não provocasse estresse devido à densidade -, pesados e divididos por sorteio em: três tanques de tilápias machos submetidas ao estresse $\mathrm{e}$ outros três sem estresse (controle); três tanques de tilápias fêmeas submetidas ao estresse e outros três sem estresse (controle).

O estresse aplicado ao experimento foi por redução da taxa de oxigênio dissolvido na água para aproximadamente $1,5 \mathrm{mg} / \mathrm{L}$ durante 18 dias. Para isso, os fluxos dos tanques contendo os animais submetidos ao estresse foram ajustados para $0,415 \mathrm{~L}$ de água por minuto para cada quilo de peixe, e os registros de ar foram deixados ligeiramente abertos. Já os tanques contendo os animais-controle foram ajustados para $1,25 \mathrm{~L}$ de água por minuto para cada quilo de peixe, e os registros de ar foram deixados abertos totalmente (Tab. 1). O monitoramento do oxigênio e a temperatura da água nos tanques eram feitos quatro vezes ao dia $(9,13,17 \mathrm{e} 21 \mathrm{~h}$, utilizando o oxímetro modelo YSI 55. $\mathrm{pH}$ e nitrito foram medidos a cada dois dias por método colorimétrico.

Após 18 dias de estresse, de cada indivíduo anestesiado com quinaldina $(1 \mathrm{~mL} / 10 \mathrm{~L})$ foram coletados $3 \mathrm{~mL}$ de sangue por punção cardíaca, utilizando seringas descartáveis de $3 \mathrm{~mL}$ e agulhas descartáveis $25 \times 8$. Desse volume de

\footnotetext{
${ }^{1}$ Merck Brasil - São Paulo, Brasil
} 
sangue, $250 \mu \mathrm{L}$ foram acondicionados em microtubos contendo solução de ácido etilenodiaminotetraacético (EDTA) a 10\%, para centrifugação e produção de plasma e posterior determinação dos valores de proteína total, por refratometria, e perfil protéico eletroforético, segundo técnica descrita por Naoum (1990) modificada (fitas de gel de agarose, tampão TRIS e $45 \mathrm{~min}$ de corrida) em cuba de fonte para eletroforese $^{2}$. As fitas foram lidas, utilizando o software CELM para determinação dos valores relativos e absolutos de albumina e globulinas.

Tabela 1. Fluxo das caixas regulado de acordo com o peso das tilápias, machos e fêmeas, em cada caixa $(\mathrm{L} / \mathrm{min} / \mathrm{kg})$

\begin{tabular}{cccccc}
\hline \multicolumn{5}{c}{ Estressado } \\
\hline Macho & Peso & Fluxo $(\mathrm{L} / \mathrm{min})$ & Fêmea & Peso & Fluxo (L/min) \\
Caixa 12 & $8.2 \mathrm{~kg}$ & 3,40 & Caixa 1 & $9.2 \mathrm{~kg}$ & 3,82 \\
Caixa 13 & $5.0 \mathrm{~kg}$ & 2,07 & Caixa 4 & $9.0 \mathrm{~kg}$ & 3,73 \\
Caixa 5 & $9.5 \mathrm{~kg}$ & 3,94 & Caixa 6 & $9.0 \mathrm{~kg}$ & 3,73 \\
& & Controle & & & \\
\hline Macho & Peso & Fluxo $(\mathrm{L} / \mathrm{min})$ & Fêmea & Peso & Fluxo (L/min) \\
\hline Caixa 11 & $9.5 \mathrm{~kg}$ & 11,87 & Caixa 2 & $9.0 \mathrm{~kg}$ & 11,25 \\
Caixa14 & $7.4 \mathrm{~kg}$ & 9,25 & Caixa 3 & $8.0 \mathrm{~kg}$ & 10,0 \\
Caixa 15 & $8.0 \mathrm{~kg}$ & 10,0 & Caixa 19 & $8.6 \mathrm{~kg}$ & 10,75
\end{tabular}

*O cálculo do consumo de oxigênio $(\mathrm{CO})$ foi baseado na equação: $\mathrm{CO}=(1000 /$ peso $) \mathrm{x}$ (peso) ${ }^{0,82}$ sendo o peso em gramas, segundo Kubitza (1998).

$\mathrm{O}$ ensaio foi realizado em delineamento inteiramente ao acaso, em arranjo fatorial $2 \times 2$ (duas condições de estresse e dois sexos). Foi aplicado teste de normalidade para verificar a distribuição das variáveis e, para aquelas que não tiveram distribuição normal (albumina\%, $\gamma$ globulina e $\gamma$-globulina\%), foi feito um ajuste de transformação utilizando $\log \mathrm{x}+1$. Os valores médios foram comparados pelo teste Tukey a $5 \%$ de probabilidade. Foi calculada também a correlação das variáveis analisadas. Para tal, empregou-se o programa SAS/1994.

\section{RESULTADOS}

Durante o período do estudo, a temperatura da água dos tanques variou de 26,8 a $28,1^{\circ} \mathrm{C}$, média de $27,7^{\circ} \mathrm{C}$; o $\mathrm{pH}$ variou de 7,4 a 7,8 ; o nitrito manteve-se menor que 0,3 , e o oxigênio dissolvido no tanque do grupo dos estressados variou de 1,05 a $2,63 \mathrm{mg} / \mathrm{L}$ e nos tanques do grupo-controle de 4,15 a 4,96mg/L (Tab. 2).

${ }^{2}$ Cuba Fonte para eletroforese ARGOS 12 - Techow Instrumentos Científicos Ltda - São Paulo/Brasil; 110v
A corrida de eletroforese utilizada para a análise de perfil protéico das tilápias identificou albumina, $\alpha$ e $\beta$-globulinas juntas e $\gamma$-globulina (Fig. 1).

Quanto aos valores absolutos e relativos de $\alpha+\beta$ globulinas e os valores relativos de albumina e $\gamma$ globulina, não se observou interação significativa de tratamento versus sexo. Para os valores de proteína total e os absolutos de albumina e $\gamma$ globulina, a interação tratamento versus sexo foi significativa.

Após o estresse por hipóxia, os valores relativos do nível sérico de albumina e $\gamma$-globulina das tilápias diminuíram significativamente, e o valor relativo de $\alpha+\beta$-globulinas aumentou $(\mathrm{P}<0,05)$ (Tab. 3).

Os machos estressados apresentaram valor mais alto de proteína total em relação às fêmeas $\mathrm{e}$ estas valores maiores de albumina e $\gamma$-globulina do que os machos (Tab. 5). No grupo-controle, as fêmeas apresentaram maiores valores $(\mathrm{P}<0,05)$ de proteína total e albumina do que os machos (Tab. 6). 
Melo et al.

Tabela 2. Valores de oxigênio (mg/L), média de três dias de medição, de tilápias segundo a caixa e o dia

\begin{tabular}{ccccccc}
\hline Caixa/dia & $1,2,3$ & $4,5,6$ & $7,8,9$ & $10,11,12$ & $13,14,15$ & $16,17,18$ \\
\hline \multicolumn{7}{c}{ Controle } \\
\hline 2 & 4,88 & 4,77 & 4,96 & 4,83 & 4,70 & 4,74 \\
3 & 4,68 & 4,83 & 4,89 & 4,89 & 4,89 & 4,83 \\
11 & 4,61 & 4,89 & 4,76 & 4,75 & 4,90 & 4,89 \\
14 & 4,95 & 4,65 & 4,88 & 4,95 & 4,89 & 4,71 \\
15 & 4,58 & 4,65 & 4,78 & 4,82 & 4,86 & 4,81 \\
19 & 4,68 & 4,79 & 4,90 & 4,88 & 4,74 & 4,86 \\
\hline & & Estressado & & & 1,72 \\
1 & 2,11 & 1,63 & 1,64 & 1,83 & 1,77 & 1,71 \\
4 & 2,29 & 1,85 & 1,76 & 1,86 & 1,76 & 1,64 \\
5 & 2,31 & 1,84 & 1,62 & 1,89 & 1,69 & 1,69 \\
6 & 2,32 & 1,87 & 1,65 & 1,79 & 1,61 & 1,74 \\
12 & 2,15 & 1,86 & 1,73 & 1,82 & 1,72 & 1,74
\end{tabular}

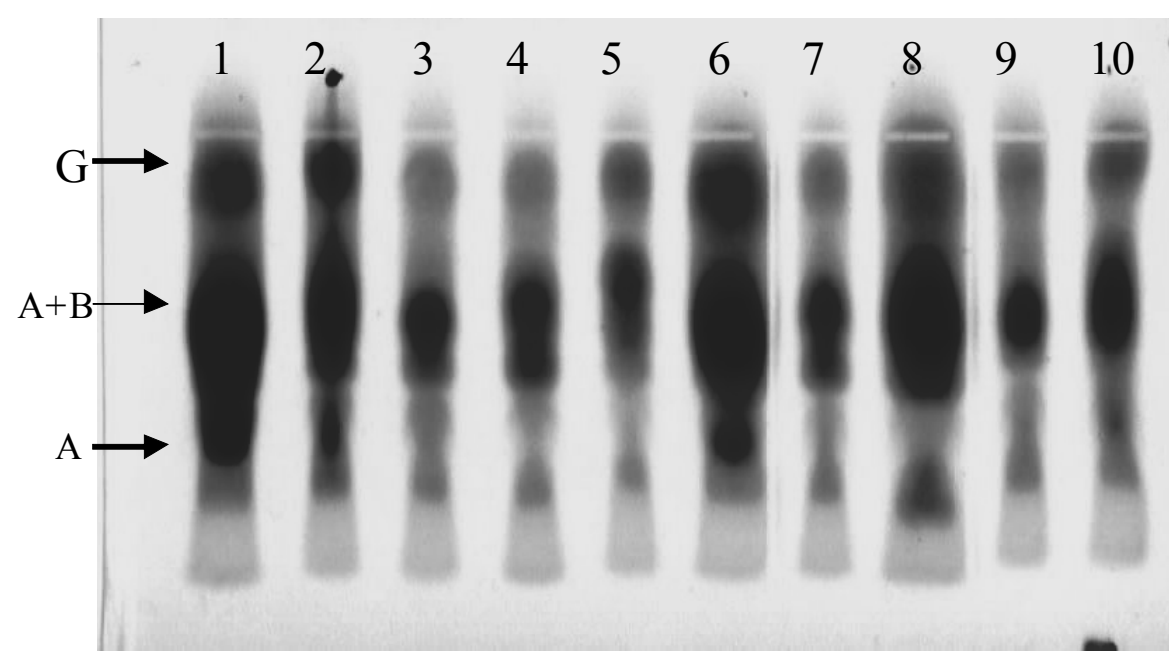

Figura 1. Fita de gel de agarose após a corrida de eletroforese da distribuição da fração de proteína do soro de tilápia. ( 1 a 10 = indivíduos, $\mathrm{A}=$ albumina, $\mathrm{A}+\mathrm{B}=\alpha$ e $\beta$-globulinas juntas, $\mathrm{G}=\gamma$-globulina $)$.

Tabela 3. Médias e desvio-padrão do perfil proteico eletroforético de tilápias dos grupos-controle e estressado

\begin{tabular}{lcc}
\hline Variável & Controle & Estressado \\
\hline Albumina (\%) & $15,38 \pm 0,65 \mathrm{a}$ & $12,16 \pm 0,47 \mathrm{~b}$ \\
$\alpha+\beta$-globulina (g/dL) & $3,37 \pm 0,07 \mathrm{a}$ & $3,98 \pm 0,11 \mathrm{a}$ \\
$\alpha+\beta$-globulina (\%) & $67,34 \pm 1,23 \mathrm{~b}$ & $74,10 \pm 0,52 \mathrm{a}$ \\
$\gamma$-globulina (\%) & $16,43 \pm 0,74 \mathrm{a}$ & $13,74 \pm 0,38 \mathrm{~b}$
\end{tabular}

Médias seguidas de letras distintas na linha indicam diferença significativa pelo teste Tukey $(\mathrm{P}<0,05)$. 
Tabela 4. Médias e desvio-padrão das variáveis bioquímicas do sangue de tilápias fêmeas e machos

\begin{tabular}{lcc}
\hline Variável & Fêmea & Macho \\
\hline Albumina (\%) & $14,75 \pm 0,56 \mathrm{a}$ & $12,64 \pm 0,62 \mathrm{~b}$ \\
$\alpha+\beta$-globulina (g/dL) & $3,79 \pm 0,07 \mathrm{a}$ & $3,13 \pm 0,09 \mathrm{a}$ \\
$\alpha+\beta$-globulina (\%) & $71,02 \pm 0,55 \mathrm{a}$ & $70,50 \pm 1,39 \mathrm{a}$ \\
$\gamma$-globulina $(\%)$ & $14,19 \pm 0,43 \mathrm{~b}$ & $16,02 \pm 0,759 \mathrm{a}$ \\
\hline
\end{tabular}

Médias seguidas de letras distintas na linha indicam diferença significativa pelo teste Tukey $(\mathrm{P}<0,05)$.

Tabela 5. Médias e desvio-padrão do perfil proteico eletroforético de tilápias do grupo estressado

\begin{tabular}{lcc}
\hline Variável & Fêmea & Macho \\
\hline Proteína total $(\mathrm{g} / \mathrm{dL})$ & $4,25 \pm 0,61 \mathrm{~b}$ & $5,56 \pm 0,55 \mathrm{a}$ \\
Albumina $(\mathrm{g} / \mathrm{dL})$ & $0,679 \pm 0,033 \mathrm{a}$ & $0,515 \pm 0,036 \mathrm{~b}$ \\
$\gamma$-globulina $(\mathrm{g} / \mathrm{dL})$ & $0,717 \pm 0,031 \mathrm{a}$ & $0,619 \pm 0,023 \mathrm{~b}$ \\
\hline
\end{tabular}

Médias seguidas de letras distintas na linha indicam diferença significativa pelo teste Tukey $(\mathrm{P}<0,05)$.

Tabela 6. Médias e desvio-padrão do perfil proteico eletroforético de tilápias do grupo controle

\begin{tabular}{lcc}
\hline Variável & Fêmea & Macho \\
\hline Proteína total $(\mathrm{g} / \mathrm{dL})$ & $5,35 \pm 0,58 \mathrm{a}$ & $4,50 \pm 0,47 \mathrm{~b}$ \\
Albumina $(\mathrm{g} / \mathrm{dL})$ & $0,890 \pm 0,050 \mathrm{a}$ & $0,626 \pm 0,042 \mathrm{~b}$ \\
$\gamma$-globulina $(\mathrm{g} / \mathrm{dL})$ & $0,792 \pm 0,03 \mathrm{a}$ & $0,824 \pm 0,05 \mathrm{a}$ \\
\hline
\end{tabular}

Médias seguidas de letras distintas na linha indicam diferença significativa pelo teste Tukey $(\mathrm{P}<0,05)$.

$\mathrm{Na}$ Fig. 2, mostra-se o desdobramento da condição de estresse/sexo ao comparar os grupos-controle e estressado, dentro de sexo, para o perfil proteico eletroforético. O estresse por hipóxia provocou diminuição significativa de proteína total e dos valores absolutos de albumina nas fêmeas, e aumento de proteína total e diminuição de $\gamma$-globulina nos machos.
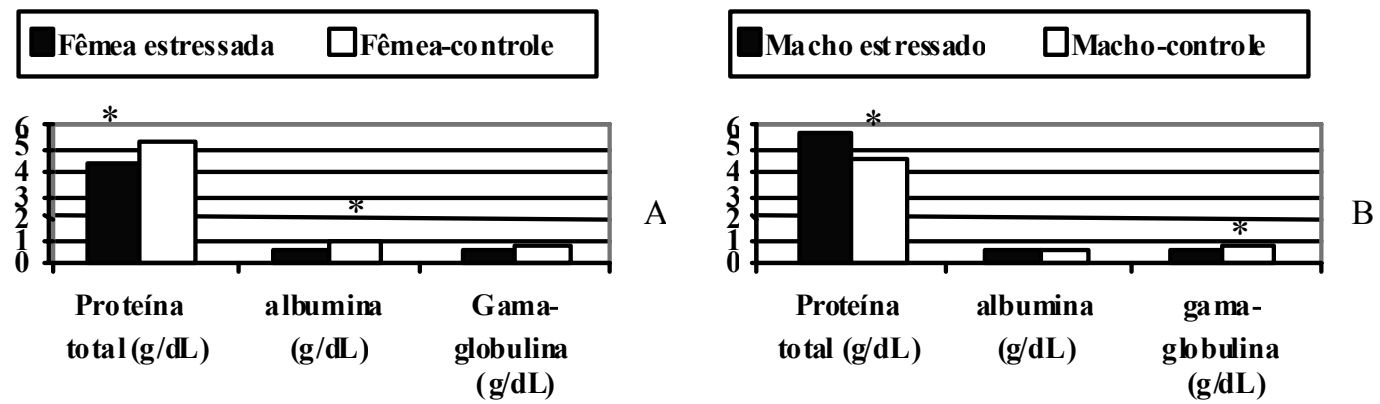

Figura 2. Valores de proteína total, albumina e gama-globulina de tilápias dos grupos-controle e estressado, fêmeas (A) e machos $(\mathrm{B})$. *Diferença significativa $(\mathrm{P}<0,05)$ pelo teste Tukey entre os grupos.

\section{DISCUSSÃO}

O estresse devido à hipóxia reduz a taxa de crescimento e desenvolvimento, promove mudanças morfológicas, alterações comportamentais e uma variedade de ajustes metabólicos e fisiológicos em várias etapas da vida do peixe (Adolph, 1983). Segundo Smart (1981), para salmonídeos, o mínimo de oxigênio dissolvido requerido é $5-6 \mathrm{mg} / \mathrm{L}$, ao passo que, para bagre americano (Ictalurus pumctatus) e espécies de tilápia, o mínimo é de $3 \mathrm{mg} / \mathrm{L}$. Valores menores que estes seriam considerados estressantes. Durante o experimento, nenhum 
animal morreu devido ao tratamento imposto. Isso sugere que a linhagem de tilápia utilizada é capaz de resistir bem a ambientes com baixos níveis de oxigênio dissolvido.

Neste trabalho, a concentração de proteína total aumentou no grupo dos machos estressados e diminuiu nas fêmeas. A determinação da concentração de proteína total no plasma e de suas frações é de grande importância clínica, pois sua concentração plasmática é responsável pela pressão coloidosmótica desse líquido corporal. Leamaster et al. (1990) observaram níveis séricos de proteína total maiores em fêmeas de tilápias de água doce expostas à água salgada, que em machos. Tavares-Dias et al. (2004), ao pesquisarem a influência de vários parâmetros sanguíneos na primeira maturação gonadal de carpa comum (Cyprinus carpio), não encontraram diferença nos níveis séricos de proteína total entre machos e fêmeas.

A proteína total é alterada principalmente por mudanças no volume plasmático. Um aumento é causado por mudança de fluido do plasma para o compartimento intracelular e uma diminuição pode ser causada por hidratação do plasma. A saída dos fluidos do plasma é causada por desequilíbrio osmótico entre os compartimentos extracelular e intracelular, e qualquer estresse que induz tal desequilíbrio pode levar a um aumento de proteína no plasma (McDonald e Milligan, 1992). Segundo Milligam e Wood (1982), o total de proteína plasmática em truta arco-íris aumentou em resposta ao exercício intenso e à exposição ao ambiente com baixo $\mathrm{pH}$. Hrubec et al. (2000) e Montero et al. (2001) também observaram aumento das proteínas totais em híbridos de tilápia (Oreochromis niloticus $x$ O. Mossambicus $x$ O. aureus) e de dourada (Sparus aurata), respectivamente, criados em alta densidade em relação ao grupo de baixa densidade. Dobsíková et al. (2006), ao estudarem o efeito do piretroide cypermethrina em carpa comum, por $96 \mathrm{~h}$, observaram que esse piretroide diminuiu os níveis de proteína total, albumina e globulinas no plasma sanguíneo. Khalaf-Allah (1999) observou aumento de proteína total, globulinas e $\operatorname{IgM}$ em tilápias nilóticas não imunizadas com antígeno de Staphylococcus aureus, expostas a vários tipos de pesticida por 30 dias.

Os valores médios das $\alpha+\beta$-globulinas aumentaram no grupo estressado. De acordo com
Thrall (2007), o aumento no teor de $\alpha$-globulinas é inespecífico e de importância diagnóstica limitada, é a inflamação aguda é a causa mais comum. No presente trabalho, a $\gamma$-globulina diminuiu após o estresse por hipóxia. Essa diminuição foi devido à diminuição dessa proteína no grupo de machos. Segundo Harris e Bird (2000), a testosterona reduz o número de células produtoras de anticorpos, e isso pode explicar por que os níveis dessa proteína foram menores nos machos. De acordo com Hoeger et al. (2005), machos de truta arco-íris expostos a efluentes de esgoto e injetados com Aeromonas salmonicida apresentam títulos mais altos de $\mathrm{IgM}$ em relação às fêmeas. Dentre as proteínas do plasma, as imunoglobulinas destacam-se por suas funções na imunidade. Essas proteínas desempenham papel importante no mecanismo de defesa imune humoral por suas características em reconhecer e interagir com componentes estranhos no organismo. De acordo Wechsler et al, (1986), a dose de $100 \mathrm{mg} / \mathrm{kg}$ de triamcinolone, um glicocorticoide sintético, diminui os níveis de anticorpos circulantes em striped bass (Morone saxatilis) exposto ao vírus da infecção necróticopancreática (IPNV). Maule e Schreck (1990) observaram diminuição da atividade de células produtoras de anticorpos e do título de IgM circulante em coho salmon após estresse agudo por hipóxia. Chen et al. (2002) observaram supressão do nível plasmático de IgM após a exposição de tilápias à baixa temperatura $\left(12^{\circ} \mathrm{C}\right)$, por períodos de 30 minutos e 2 horas.

No presente estudo, o estresse por hipóxia provocou alterações no nível de albumina. Segundo Hasegawa et al. (2002), sua síntese é influenciada pela nutrição, balanço hormonal, estado geral do fígado e estresse. Um fator que pode ter contribuído para a diminuição da albumina do grupo estressado foi o reduzido consumo de ração, pois nesse grupo foram observadas, poucos minutos após a alimentação, sobras de ração no tanque. Segundo Smart (1981), um dos primeiros indícios de estresse dos peixes devido à redução da concentração de oxigênio dissolvido é a rejeição de alimento. De acordo com Leite (1995), uma das funções da albumina é servir como reservatório móvel de aminoácidos do fígado para os tecidos periféricos. Nesses tecidos, a albumina pode ser quebrada intracelularmente para fornecer aminoácidos necessários à síntese de novas proteínas. 
Embora a tilápia seja o segundo peixe mais criado no mundo, existem poucos relatos que mostrem diferenças no perfil eletroforético e no estresse entre os sexos. No presente trabalho, a porcentagem de albumina e o nível relativo de $\gamma$ globulina sofreram influência do sexo. Segundo Tavares-Dias et al. (2004), em teleósteos, o dimorfismo sexual que ocorre em relação às características hematológicas pode estar associado à presença de andrógenos. Leamaster et al. (1990) também observaram níveis séricos de albumina e globulinas mais altos em fêmeas de tilápias quando expostas a água salgada que em machos.

\section{CONCLUSÕES}

Conclui-se que o estresse provocado pela hipóxia provoca alterações no perfil proteico de tilápias da linhagem chitralada e que algumas das variáveis estudadas foram influenciadas pelo sexo.

\section{AGRADECIMENTOS}

Agradecemos à Fazenda Geneforte pela doação dos exemplares de tilápia e pelo apoio, ao Laboratório de Toxicologia da Escola de Veterinária da UFMG, e ao $\mathrm{CNPq}$ pelo apoio financeiro.

\section{REFERÊNCIAS BIBLIOGRÁFICAS}

ADOLPH, E.F. Uptakes and uses of oxigen, from gametes to maturity. Resp. Phisiol., v.53, p.135-160, 1983.

BARTON, B.A.; IWAMA, G.K. Physiological changes in fish from stress in aquaculture with emphasis on the response and effects of corticosteroids. Ann. Rev. Fish Dis., v.1, p.3-26, 1991.

CANAVESSI, A.M.O; CHIACCHIO, S.B.; CURY, P.R. Valores do perfil eletroforético das proteínas séricas de bovinos da raça nelore criados na região de Botucatu, São Paulo: Influência dos fatores etários e sexuais. Arq. Inst. Biol., v.67, p.9-17, 2000.

CARLSON, R.E.; ANDERSON, D.P.; BODAMMER, J.E. In vivo cortisol administration suppresses the in vitro primary immune response of winter flounder lymphocytes. Fish Shellfish Immunol., v.3, p.299-312, 1993.

CHEN, W.H.; SUN, L.T.; TSAI, C.L. et al. Cold-stress induced modulation of catecholamines, cortisol, immunoglobulin $\mathrm{M}$, and leukoctte phagocytosis in tilapia. Gen. Comp. Endocrinol., v.126, p.90-100, 2002.

DOBSÍKOVÁ, R.; VELISEK, J.; WLASOW, T. et al. Effect of cypermethrin on some haematological, biochemical and histopathological parameters os common carp. Neuroendocrinol. Lett., v.27, p.91-95, 2006.

GERSHWIN, L.J. Clinical immunology. In: KENEKO.J.J. (Ed.). Clinical biochemistry of domestic animals. 4.ed. London: Academic Press, 1989. p.167-184.

GODOY, A.V.; SANTANA, A.E.; NAKAGE, A.P.M. et al. Perfil eletroforético de proteínas séricas do sangue do cordão umbilical de cães. Cienc. Rural, v.36, p.531-535, 2006.

HARRIS, J.; BIRD, D.J. Modulation of the fish immune system by hormones. Vet. Immunol. Immunopathol., v.77, p.163-176, 2000.

HASEGAWA, M.Y.; FONTEQUE, J.H.; KOHAYAGAWA, A. et al. Avaliação do perfil eletroforético das proteínas séricas em matrizes pesadas (Gallus Gallus domesticus) da linhagem Avian Farm. Rev. Bras. Cienc. Avic., v.4, p.203207, 2002.

HOEGER, B.; HITZFELD, B.; KOLLNER, B. et al. Sex and low-level sampling stress modify the impacts of sewage effluent on the rainbow trout (Oncorhynchus mykiss) immune system. Aquat. Toxicol., v.73, p.79-90, 2005.

HRUBEC, T.C.; CARDINALE, J.L.; SMITH, S.A. Hematology and chemistry reference intervals for cultured tilapia (Oreochromis hybrid).Vet. Clin. Pathol., v.29, p.7-12, 2000.

KANEKO, J.J.; HARVEY, J.W.; BRUSS, M.L. (Eds.). Clinical biochemistry of domestic animals. 5.ed. New York: Academic Press, 1997. 932p.

KHALAF-ALLAH, S.S. Effect of pesticide water pollution on some haematological, biochemical and immunological parameters in tilapia nilotica fish. Dtsch. Tierz. Wochenschr., v.106, p.67-71, 1999. 
KUBITZA, F. Qualidade da água na produção de peixes - Parte III (final). Panorama Aquicult., v.8, p.35-43, 1998.

LEAMASTER, B.R.; BROCK, J.Q.; FUJIOKA, R.S. et al. Hematologic and blood chemistry values for Sarotherodon melanotheron and a red hybrid tilapia in freshwater and seawater. Comp. Biochem. Physiol., v.97A, p.525-529, 1990.

LEITE, J.I.A. Proteínas do plasma. In: VIEIRA, E.C.; FIGUEREDO, E.A.; LEITE, J.I.A. et al. Química fisiológica. 2.ed. São Paulo: Atheneu, 1995. p.9-16.

MAULE, A.G.; SCHRECK, C.B. Changes in numbers of leukocytes in immune organs of juvenile coho salmon after acute stress or cortisol treatment. J. Aquat. Anim. Health, v.2, p.298304, 1990 .

McDONALD, D.G.; MILLIGAN, C.L. Chemical properties of the blood. In: HOAR, W.S.; RANDALL, D.J.; FARREL, A.P. (Eds.). Fish Physiology. San Diego: Academic, 1992. v.XIIB, p.55-134.

MILLIGAN, C.L.; WOOD, C.M. Intracellular and extracellular acid-base status and $\mathrm{H}^{ \pm}$ exchange with the enviroment after exaustive exescice in the rainbow trout. J. Exper. Biol., v.123, p.92-121, 1982.

MONTERO, D.; TORT, L.A.L.; VERGARA, J.M. et al. Low Viamin $\mathrm{E}$ in diet reduces stress resistence of gilthead seabream (Sparus aurata) juveniles. Fish Shellfish Immunol., v.11, p.473490, 2001.

NAOUM, P.C. Eletroforese - técnicas e diagnóstico. São Paulo: Livraria Santos, 1990.
PALTI, Y.; TINMAN, S.; CNAANI, A. et al. Comparative study of biochemical and nonspecific immunological parameters in two tilapia species (Oreochromis aureus and $O$. Mossambicus). In: INTERNATIONAL SYMPOSIUM ON TILAPIA AQUACULTURE, 5., 2000, Rio de Janeiro. Proceedings... Rio de Janeiro, 2000. p.504-511.

SMART, G.P. Aspects os water qualit producing stress in intensive fish culture. In: PICKERING, A.D. (Ed.). Stress and fish. New York: Academic Press, 1981. p.277-293.

TAVARES-DIAS, M.; BOZZO, F.R.; SANDRIN, E.F.S. et al. Células sanguíneas, eletrólitos séricos, relação hepato e esplenossomática de carpa-comum, Cyprinus carpio na primeira maturação gonadal. Acta Scient. Biol. Sci., v.26, p.73-80, 2004.

THRALL, M.A. Hematologia e bioquímica clinica veterinária. São Paulo: Roca, 2007, 582p.

TINMAN, S.; BELOTSKY, S.; AVILAR, Y. et al. Effect of long-term oral administration of peptidoglycan on growth rate and immunostimulation response of hybrid tilapia (Oreochromis eureus x O. Niloticus). In: INTERNATIONAL SYMPOSIUM ON TILAPIA AQUACULTURE, 5., 2000, Proccedings... Rio de Janeiro, 2000. p.504-511

WECHSLER, S.; McALLISTER, P.; HETRICK, F. et al. Effect of exogenous corticosteroids on circulating virus and neutralizing antibodies in striped bass Morone saxatilis infected with infections pancreatic necrosis virus. Vet. Immunol. Immunopathol., v.12, p.305-311, 1986. 